monograph on the anatomy of Tarsius, and comparative studies on the cerebral cortex of Tarsius, the brain of Orycteropus, and the retina of primates. $\mathrm{He}$ was, however, essentially an experimental anatomist, and he received a great stimulus from his contact with American anatomists during the year which he spent at Johns Hopkins University as a Rockefeller research fellow. As a consequence of the experience which he gained from this visit, Woollard published the results of several important experimental studies ; for example, the development of the vascular patterns of the limbs as demonstrated by the micro-injection of living embryos, the phagocytis activity of hæmal glands, and the vital staining of the leptomeninges. Probably some of his best work was that dealing with the innervation of the heart and blood vessels, which was completed in 1925 and 1926. In 1927 he published his "Recent Advances in Anatomy" which attracted vigorous attention to the development of experimental anatomy in other countries, and did much to stir his contemporary colleagues to work for the revivification and reorientation of anatomical teaching and research in Great Britain.

During his brief tenure of office in the University of Adelaide, Woollard made full use of his opportunities by his detailed and original studies of the Australian brain and of the distribution of blood-groups among the native populations. On his return to England, he concentrated his research activities on the peripheral nervous system. He had acquired extraordinary skill with the difficult technique of vital staining with methylene blue, and he applied this technique to very good effect in his experimental studies of peripheral innervation. Mention has already been made of his work on the innervation of the heart and bloodvessels. This is work to which continual reference is made by those who are concerned with the neural control of the cardio-vascular system. He applied the same technical methods to problems of cutaneous innervation, and for this purpose he used himself as an experimental subject. He aimed at correlating the localization of different sensory spots in his own skin with different morphological types of nerve ending, a study which involved a considerable amount of discomfort in the small operations which he permitted to be carried out on himself in order to obtain material for histological examination. The results of some of these observations were published during 1936 and 1937, and in 1938 he was elected a fellow of the Royal Society.

Woollard died in the middle of a scientific career when he had already achieved much, but his research activities were so productive that his colleagues confidently looked forward to a great deal more from him and from those whose work he was directing in his department. More than this, he aspired to raise the science of anatomy to a level of achievement and activity which he regarded as its proper status. His energetic example had inspired many of his fellow anatomists to work with him to this end, and the first fruits of these efforts were already becoming evident. Hence, his death will be felt as an extremely serious loss for the subject which he represented.
His friends mourn a devoted worker who spared himself not at all in his scientific and departmental duties, a colleague who was always ready to give help and advice in all manner of difficulties, and a man who had a very lovable character.

W. E. Le Gros Clark.

\section{Mr. A. B. MacDowall}

We regret to record the death, which occurred on January 10, of Alexander Baird MacDowall, who was a frequent contributor to NATuRE a generation ago.

Mr. MacDowall was born at Alloa on December 18, 1843. At fifteen years of age he was sent to the Old College in High Street, Glasgow, long since swept away, where he came into contact with Prof. W. Thomson, afterwards Lord Kelvin. Next he went to Berlin, returning after six months to take his degree at Glasgow. This was followed by a trip to Melbourne in a sailing vessel for reasons of health, the return journey being made via Cape Horn.

On his return to Great Britain, Mr. MacDowall settled in London and started upon a career of general journalism, working in the British Museum and at the Patent Office. There he met Sir William Harcourt, Thomas Carlyle and others, including D. E. Hughes, inventor of the microphone. He followed closely the development of the telephone, and long before it was in general use, he had an experimental installation set up in his house.

About this time, Mr. MacDowall was contributing to NATURE, and also to the Royal Meteorological Society, on the subject of terrestrial and solar meteorology and the relationship between them. In 1895 he brought out a small book "Weather and Disease : a Curve History of their Variations" ; the mode of representation adopted was that commonly used at the time to illustrate the relation between two variables, namely, the production of smoothed. curves recording the averages of five or ten consecutive values. A similar method was used in a paper on the relation of terrestrial weather statistics to the sunspot cycle presented to the Royal Meteorological Society in 1897.

In recent years, Mr. MacDowall travelled a good deal in the British Isles and on the Continent, settiing down some twelve years ago at Rothesay in the Isle of Bute. He retained to the end his lively interest in scientific developments. His wife, Emily, a daughter of William Liddon and Emily Howard, died in 1935 .

WE regret to announce the following deaths :

Paul Séjourné, free academician of the Paris Academy of Sciences, who was known for his work on the design and structure of bridges, aged eightyseven years.

Prof. Josef Šimon, professor of roentgenology and radiology in the Masaryk University, Brno, aged forty-one years. 